\title{
O CORPO QUE FALA: A (IM)POSSIBILIDADE DE REGULAÇÃO DAS NOVAS EXPERIÊNCIAS CORPORAIS PELO DIREITO
}

\author{
THE BODY THAT SPEAKS: THE (IM)POSSIBILITY OF \\ REGULATION OF NEW BODY EXPERIENCES BY LAW
}

\author{
Doglas Cesar Lucas \\ Pâmela Copetti Ghisleni
}

A Igreja diz: O corpo é uma culpa. A ciência diz: 0 corpo é uma máquina. A publicidade diz: $O$ corpo é um negócio. O corpo diz: Eu sou uma festa.

Eduardo Galeano

\begin{abstract}
RESUMO
0 racionalismo do século XVII inaugurou uma nova forma de pensar ao estabelecer que o acesso ao mundo se dava por meio da racionalidade. A concepção individualista de sociedade surgida a partir do século XVIII, em que pese tenha colocado o indivíduo no centro, o fez a partir da sua dimensão psíquica, relegando-se um lugar secundário ao corpo biológico. Nessa perspectiva, privilegia-se a mente em detrimento da carne. No século XX, contudo, Freud rememora a temática do corpo ao introduzir novamente o ser em sua materialidade corpórea. Sendo assim, é restaurada e aprofundada a temática da carne, da carcaça, do corpo orgânico e biológico. Por conseguinte, o presente estudo objetiva, valendo-se do método hipotético-dedutivo, analisar a (im)possibilidade de regulação do corpo, sobretudo feminino, pelo direito contemporâneo e suas repercussões práticas para as mulheres para, ao final, concluir que o corpo e a suas narrativas estão na base da desigualdade e da opressão de gênero.
\end{abstract}

Palavras-Chave: Corpo. Direito. Feminismo. Mulher. Sexualidade.

\section{ABSTRACT}

The rationalism of the seventeenth century inaugurated a new way of thinking to establish that access to the world occurred through rational- 
ity. The individualist conception of society that emerged from the eighteenth century, despite having placed the subject in the center, made it from its psychic dimension, relegating the biological body to the second place. In this perspective, the emphasis is in the mind at the expense of meat. In the twentieth century however, Freud recalls the theme of the body to enter again the individual in his materialistic body. Therefore, it was restored and deepened the theme of meat, carcass, organic and biological body. Thus, the present study aims, from the hypothetical-deductive method, to analyze the (im)possibility of body regulation, especially the female one, by the contemporary law and its practical implications for women to, in the end, conclude that the body and their narratives are at the root of inequality and gender oppression.

Keywords: Body. Law. Feminism. Woman. Sexuality.

\section{CONSIDERAÇÕES INTRODUTÓRIAS}

Em A Pele que Habito, o sempre profundo - e nesse caso, extremamente sádico - Pedro Almodóvar coloca-nos a pensar sobre quem é o eu que habita a pele, quem é o ser que mora no corpo. A experiência do filme é extremamente rica na medida em que narra a história de Robert, um médico cujas vivências não lhes permitiram elaborar o luto pela ausência (talvez mais física) de sua amada esposa. Norma, filha do cientista, é uma jovem atormentada por ter presenciado a morte da mãe e, em um ato verdadeiramente limiar, é estuprada por Vicente. A partir daí, o sentimento de vingança reconforta Robert, que passa a impor uma transexualização forçada ao rapaz, que é batizado de Vera. 0 espectador questiona-se, então, sobre o fato de a cobaia ter assumido, ou não, as pressupostas características do novo corpo (e do novo sexo). Percebe-se que ele o faz, mas apenas como forma de sobreviver no confinamento criado por Robert. Ao final, portanto, descobre-se que Vera sempre foi apenas o invólucro que encapsulava Vicente.

Quem nos reconheceria se fossemos emoldurados em outro sexo, em outra pele, em outro corpo, em outro rosto, em outro riso, ainda que mantivéssemos nossa essência na íntegra (se é que isto é possível)? É que a pele talvez seja, de fato, o que há de mais profundo, para lembrar uma máxima de Paul Valéry e, ao mesmo tempo, de mais escancarado. 
O corpo é o intérprete ativo ou passivo daquilo que somos, no sentido de que ele permite a objetivação da subjetividade do ser. Ele possibilita (ou não) visibilizar o que há de mais profundo. É na psique, mas também no corpo e na pele, que se inscrevem os acontecimentos particulares da história de cada indivíduo. Com isso, pretende-se demonstrar que não há abismo entre corpo e ser, carcaça e mente. Na realidade, o que separa cada "oposto" desse par binário é uma linha tênue que permite esconder ou desnudar, solapar ou revelar.

Diante de todas essas turbulências que envolvem o corpo psíquico e o corpo somático, o presente artigo procura trabalhar com a ideia de que somente o corpo biológico permite ao sujeito agarrar-se a sua própria existência. Optou-se por empregar especial destaque à questão das mulheres, na medida em que, por muito tempo na história e ainda hoje, o corpo feminino é um controverso palco no qual se inscrevem ideologias, discursos e narrativas que determinam expectativas estereotipadas de papéis sexuais. É que nesse jogo binário do macho e da fêmea, a história, a filosofia, a medicina, a pedagogia, a psicologia e, em última instância, o direito, se encarregaram (e ainda se encarregam) de fazer a mulher pequena, inferior, frívola.

Para realização da pesquisa, estudaram-se obras afins à temática disponíveis em meios físicos e na rede mundial de computadores. Para tanto, foram fundamentais as contribuições de uma imensa gama de disciplinas, a exemplo da antropologia, da psicologia, da psicanálise, da medicina, da história e do direito. 0 primeiro ponto destina-se a tecer alguns aportes relativos a aproximações entre corpo e ser, na tentativa de justificar e demonstrar que o corpo psíquico e biográfico não se aparta do somático e biológico. No segundo e no terceiro itens, passa-se à abordagem das especificidades feminina no tocante ao corpo e às relações de poder que em torno (e nele) orbitam. Por fim, o último ponto da pesquisa parte do princípio de que, na medida em que o século XX coloca na ordem do dia a questão do corpo materialmente considerado, o sistema jurídico também passa a regular (e castrar) as liberdades que a experiência corporal oferece aos sujeitos, especialmente às mulheres.

Francis Bacon dizia se surpreender com o fato de que em um açougue encontrava sempre um animal, e não um homem. De fato, somos carcaça 
em potência. E sendo isso, já somos muito. Contudo, paradoxalmente e de forma quase que esquizofrênica, não podemos ser somente carne, sob pena de reduzir-se Vicente à Vera, pois um corpo nunca é só um corpo. Ele é um infinito de possibilidades e devires a decifrar no percorrer da nossa existência.

\section{O CORPO ENTRE BIOLOGIA E BIOGRAFIA, ENTRE NATUREZA E CULTURA: ITINERÁRIOS DE UMA AMBIVALÊNCIA}

A natureza e a cultura são dois termos utilizados para designar a ambivalência com a qual o corpo se expressava nas sociedades primitivas e a equivalência à qual foi reduzido na sociedade contemporânea pelo conjunto de códigos que o governam e pelos mais variados tipos de inscrições que o alcançam. Nas sociedades primitivas o corpo não era uma entidade anatômica que podia ser percebida de modo isolado e que identificamos como a singularidade de cada indivíduo. 0 corpo era, nessa lógica, comunitário, social, uma zona na qual se expressavam os sentidos e os signos do grupo. Natureza e cultura não eram separadas neste tempo e o corpo era o palco das representações da comunidade. Por isso, o corpo não tinha uma identidade aqui, mas um lugar. Diferentemente, nas sociedades pós-tradicionais, o corpo adquire um valor, lhe é atribuído um sentido próprio. Cultiva-se o corpo e, aos poucos, se vai separando sua biologia da sua biografia. Nesse itinerário, mente e corpo também são separados.

O corpo já foi interpretado pela lente de diferentes saberes e estruturas, como organismo a ser curado, como força de trabalho, como "carne" em busca de perdão, como inconsciente a ser liberto, como suporte de um conjunto de sinais a serem transmitidos. Como significado flutuante, o corpo, destaca Galimberti (2010), confunde os códigos provenientes de diferentes estruturas narrativas, com uma operação simbólica que consiste em compor aquela disjunção em qual cada código se articula quando divide o verdadeiro do falso, o bom do mal, etc., obtendo uma espécie de bivalência na qual o positivo e o negativo se refletem, produ- 
zindo aquela realidade imaginária que se encontra na origem de toda a especulação sobre o tema.

Propondo-se como isto, mas também como aquilo, o corpo, que se concede a todas as inscrições e também às reduções, com sua ambivalência provoca toda a espécie de oscilações e estratificações. Do centro de irradiação simbólica nas comunidades primitivas, o corpo foi transformado no ocidente em o negativo de cada valor, que o saber, com a cumplicidade do poder, tratou de ampliar. Do corpo, descrito por Platão em Fédon (1996), tomado de medos, paixões e prazeres, do qual a alma deve manter isolamento para ser pura, ao corpo cheio de desvios e maleficências denunciado no discurso bíblico, da dilaceração cartesiana da sua unidade à sua anatomia operada pela ciência, o corpo parece ver concluída parte da sua história com a sua redução à força de trabalho na economia, na qual é mais evidente a ideia de acúmulo de valor, mas que também desafia o corpo sobre a perspectiva da sua ambivalência.

$\mathrm{O}$ desafio a que se submete o corpo não significa que se oponha a qualquer coisa ou qualquer um, mas simplesmente que não se deixa tomar por uma plenitude de sentido e de valor, não porque tenha objeções ou restrições, e sim porque a plenitude dos sentidos e dos valores cresce sobre a sua mortificação. Ao mesmo tempo em que se retira o nome, sua identidade, torna possível a elaboração de novos e contra sentidos. Ao dissolver o seu nome, resolve sua identidade na relação com suas adjacências.

A constatação da redução da ambivalência simbólica do corpo a um equivalente geral de valor não é um prenúncio da libertação do corpo, da restituição de sua expressão contra a repressão de algum tipo de sistema. Estranha e paradoxalmente essa descoberta do corpo, que é apresentada como premissa para sua libertação, é utilizada, refere Galimberti (2010, p. 13):

Per liquidarlo definitivamente nell'ingranaggio del sistema e della sua produzione che, non contenta di sfruttare la sua forza-lavoro, ne sfrutta anche la forza del Desiderio, allucinandolo com quegli ideali di bellezza, giovinezza, salute, sessualitá che sono poi i novi valori da vendere.

O corpo ocupa um lugar no mundo e contrai hábitos em um espaço que não o ignora. Mas ao mesmo tempo, o corpo, para manter-se como tal, não pode ser colonizado pelo mundo, pois sua presença é garantida 
na possibilidade de se manter como projeto, como fora de si, como intenção, como projeção futura, continua Galimberti. As narrativas cartesianas que separaram corpo e mente reduziram o corpo a um mero objeto da natureza e desconhecem que o corpo é um espaço e tem seu próprio estatuto povoado de inúmeras formas de representação, que possui modos diversos de atuar e de revelar-se. 0 corpo é ele mesmo um espaço no mundo e até onde se estende a sua presença se estende o próprio corpo, porque aquele é o seu espaço (GALIMBERTI, 2010).

Cada ato humano revela que a presença é corpórea, sendo o corpo minha forma de aparecer. 0 vulto não é apenas uma imagem de mim, mas é eu mesmo. Não é aparição de um eu transcendental, mas a perfeita identidade entre ser e aparecer, e aceitar essa identidade é uma condição fundamental para o equilíbrio. Assim como não existe um pensamento fora da palavra que o exprime, "allo stesso modo non existe un uomo al di fuori del suo corpo, perché il suo corpo è lui stesso nella realizzazione della sua esistenza" (GALIMBERTI, 2010, p. 16). 0 corpo é um lugar de inscrição e sua forma de apresentação, cada sinal que carrega faz do corpo uma memória. 0 corpo é atravessado de existência, é a própria existência em forma de presença e aparência. Encarnando um símbolo, o corpo consigna uma identidade de grupo a qual deve assimilar-se pela remoção das diferenças. Nesse sentido, e isso tem sua faceta cruel, o corpo não diz de si mesmo, mas dos significantes que o assinalaram. Ao ser palco de inscrição, limita-se a ser o nome de um conceito. Paradoxalmente, para dominar o corpo, muito diferentemente das sociedades tradicionais que inscreviam sentidos sociais no corpo, a sociedade contemporânea não impõe sentidos, senão que esvaziam de sentidos todos os signos que o corpo poderia consignar. É flagrante, nesse aspecto, o papel da tatuagem e das marcas corporais nas sociedades tradicionais (os indígenas são um bom exemplo entre nós), que evidenciavam um sinal social presente no sujeito e não estavam prisioneiras de códigos específicos como atualmente.

Ao assumir-se como lugar para vários sentidos, o corpo é esvaziado de significados e transcende a sua própria natureza. Marcado desde diferentes códigos (disciplina, beleza, desejo, necessidades, etc.), o corpo se produz perigosamente numa transgressão, pois a aderência 
a diferentes códigos lhe impõe a negação de cada um deles em particular, tendo em vista que o jogo ambivalente se constitui com base numa relação estabelecida com seu oposto, não contemplando a polivalência com uma possibilidade presente na diferença. As muitas marcas que o corpo pode assumir lhe trouxeram o custo das identidades flexíveis, a redução das narrativas comunitárias e a estratificação dos sentidos sobre um mesmo signo. E é justamente nessa incapacidade de se narrar a priori o corpo, como local de inscrição social fechada, que se encontra a sua capacidade de reinventar-se o tempo todo e cada vez mais, como possibilidade e como vir a ser do sujeito. Ao não ser apenas uma coisa, muitos signos podem surgir, vários podem ser abandonados e muitas ressignificações positivas tendem a tomar-se definitivamente corpo. 0 caso das novas potencialidades da sexualidade reveladas no e pelo corpo se enquadram nesse cenário.

Uma forma sofisticada de perceber a identidade como uma construção social é a sua relação com o corpo e no corpo. 0 corpo carrega as características biológicas do sujeito. A identidade, por sua vez, é a construção social de sua biografia. De acordo com Eligio Resta (2011; 1997), identidade e corpo são categorias que se avizinham, se aproximam, que divergem, mas que não se confundem e que reclamam, cada uma delas, sua autonomia particular. Como unidade biológica o corpo é um acontecimento natural que tem seu próprio enredo e que escapa do controle. A cor, o gênero, a sexualidade e tantos outros atributos biológicos não são escolhas do sujeito. Como construção discursiva o corpo se manifesta como local de inúmeras representações e a sua identidade se apresenta como uma das possibilidades dessa representação. Na identidade, biologia e biografia se inter-relacionam pela elaboração de sentidos e de uma linguagem específica, codificada, que transforma a objetividade do corpo, sua natureza, em um privilegiado espaço de manifestações autênticas, particulares. Mais do que uma essencialidade, o corpo adquire uma gramática e uma semântica que lhe são próprias e que são resultados e processos de uma determinada forma de construção social. No corpo se instala uma vida social que representa mais do que uma vida biológica. A vida se manifesta no corpo, é corpo. Reclama e constitui uma identidade que garante sua biografia, sua fala e sua particular forma de ser no mundo. 
Apesar de a sociedade consumerista contemporânea parecer privilegiar e cultivar o corpo como um objeto, como um instrumento, como uma forma de potencializar a própria identidade pessoal, definitivamente ele é muito mais do que isso; se pode ler nele e em suas transformações também um projeto. Sujeito e corpo não se separam. 0 corpo não se reduz a uma imagem corpórea, estática, que "opera come un oggetto di cui possiamo avere un'immagine chiara" (FEATHERSTONE, 2009, s/p). Ele esconde e revela; carrega passado e devir. É realidade objetiva e manifestação subjetiva. 0 corpo é liberado de sua biologia, ainda que nela, e é descoberto em sua feição discursiva, como construção que habita o mundo, que se abre ao mundo e que pode se revelar de diferentes maneiras (GALIMBERTI, 2010).

O corpo não é uma superfície plana na qual o indivíduo e a sociedade escrevem seus símbolos e representações de forma desconexa e aleatória. 0 corpo nasce em um mundo sempre habitado e para ele se abre. 0 espaço do corpo é diversificado. Não é um único espaço, mas um espaço múltiplo. Nele operam várias relações ao mesmo tempo, vários espaços descontínuos e em movimento. Mas ele também se singulariza num espaço específico, que só é possível pelos processos de codificação e decodificação que o atravessam. Codificar, recodificar, descodificar são operações que particularizam as muitas representações que habitam corpo do sujeito e lhe dão identidade e reconhecimento. 0 corpo também é espaço no qual os problemas da vida do sujeito adquirem uma particular maneira de se manifestar.

Definitivamente o corpo fala e reclama. Mas o faz pela sua biografia, pelos inúmeros "eus" que lhe dão sentido histórico, afetivo, sexual, etc. Tem sua forma própria de se manifestar. Requer normas de proteção que o reconheçam em sua totalidade. A igualdade moderna protege o corpo em sua condição de igualdade abstrata e universal. Liberdade de ir e vir; liberdade de pensar; liberdade de culto, liberdade econômica. São liberdades deste tipo, liberdades de traço universal, que, em certa medida, não se ocupam das diferenças como um valor positivo. Por isso mesmo o gênero, a cor, a religiosidade, a sexualidade, verdadeiras manifestações dos diversos "eus" aprisionados no corpo biológico, foram praticamente desconsideradas, colocadas de lado, contrapostos, em nome de uma igualdade universal de tipo homogeneizadora. Nesse modelo 
moderno a identidade nacional praticamente esgota o pertencimento, e o corpo e o "eu" relacionam-se de forma pouco complexa. 0 corpo, sua biologia, parece colonizar o "eu", a sua biografia, calando-o, negando sua visibilidade como valor positivo.

Se no passado a identidade permitia apenas uma identificação quase estática, uma identidade imodificável, a identidade se libertou e dispõe de si com naturalidade e força para fazer alterações constantes na sua própria gramática de identificações. E nisso reside um problema: a biografia com a qual escrevemos nossa identidade se transforma, deixa de ser estável e passa a ser provisória e múltipla. Na formação identitária, a biologia do corpo e sua biografia se inter-relacionam de modo dinâmico. 0 corpo expressa-se por novas linguagens, visita novos ambientes, convive com novas diferenças. Essa experiência rica de encontros a que o corpo do homem se submete e é submetido na sociedade contemporânea, incitou, necessariamente e como forma identificar suas particularidades, o aparecimento de novas biografias convivendo conjuntamente e reproduzindo identidades múltiplas presentes em um só corpo.

O corpo, notadamente no mundo contemporâneo, mais do que em qualquer época, vive em diversos espaços ao mesmo tempo. Trabalho, turismo, sexualidade, educação, religiosidade, etc., são espaços habitados, a um só tempo, pelo corpo. Alguns desses lugares já referenciam uma identidade com estatuto próprio e um mapa que permite boa circulação. Outros espaços, por sua vez, são novos e desafiadores. Manter-se identificado a apenas um lugar, nesse cenário de multiplicidade, é difícil. Por isso a identidade tende a produzir novas mediações, reordenar o espaço, sua narrativa, sua história. Consegue continuar suas conexões porque é capaz de reorganizar unidades diferenciadas e de fazer novas combinações nesse mar de espaços múltiplos. Tal tarefa é importante e necessária para garantir estabilidades, mesmo que provisórias (RESTA, 2011).

Assim, vários "eus" brotam de um mesmo corpo. Não é mais um corpo proletário, apenas, ainda que possa ser também, que se esgota em demandas por redistribuição e que desconhece o mundo para além da fábrica. Tampouco o corpo se resume a um conceito de cidadão nacional. 0 corpo se desvela por completo. Fala de si, se transforma em ator múltiplo que revela pelo discurso de seus vários "eus" ao mesmo 
tempo. Um corpo, pois, descortina várias biografias que produzem sua própria memória, seu próprio estatuto de identificação que reproduz sua particularidade no mundo.

É preciso considerar ainda que o corpo é um repositório de manifestações biológicas que funcionam como código de comunicação e identificação de determinadas qualidades e características compartilhadas, e com isso a biologia de cada sujeito tende a se constituir numa instância biográfica de recontar e reproduzir a história do próprio corpo. Nesse caso, a identidade como memória conduz a uma espécie de sentido que necessita reconhecer e valorizar atributos objetivos do próprio corpo e de sua representação biológica como elementos de diferenciação e igualdade. Cor, raça, sexualidade, idade, etc, ainda que possam ser lidos em suas dimensões simbólicas, perfilham um tipo de reconhecimento do corpo que identifica individualmente cada um de nós em particular e nos associa a um conjunto de outros semelhantes pelo compartilhamento de atributos biológicos, pela narrativa de uma biografia que identifica.

Como manifestação de uma biografia, a identidade é um traço do ser, um mecanismo de revelação de sua particularidade. A biografia como construção social é bem mais rica e complexa que sua correspondência em termos jurídicos. Enquanto o direito normatiza e reduz complexidades por meio de uma generalização congruente, a identidade se alimenta de ambivalências e de paradoxos que não podem ser tipificados pelo signo lícito ou ilícito. A identidade carrega memória e possibilidades de reconstrução permanente de sua própria representação. A biografia do sujeito fala de sua posição no mundo, de sua historicidade e de suas interações temporais e espaciais. Nesse sentido a identidade traduz uma posição de pertença, um sentido de unidade e, sobretudo, uma dada construção social que é compromissada com seu próprio estatuto. A biografia do sujeito, sua identidade, é sempre afetada pelas condições sociais em que o mesmo está inserido. Ao reafirmar sua identidade reafirma, também, uma particularidade construída socialmente, religando o sentimento de memória e definindo uma específica biografia para a biologia do corpo que ganha sua forma autêntica de linguagem e significados.

Nessa perspectiva, não há como tratar da questão do corpo sem mencionar as particularidades daquilo a que alguns atribuem a alcunha 
de "mundo feminino". Isto porque na realidade, o corpo controverso, esquizofrênico, histérico era (e ainda hoje é assim denominado) o feminino. Ele está na aurora de uma série de discussões e reivindicações que na contemporaneidade vão tratar das singularidades dos corpos "outros", do transgênero, do andrógeno e daquelas inúmeras outras formas de ser e existir às quais o ser humano parece ter sempre de nominar, para delas se apropriar. Nesse sentido e partindo dessa ideia até aqui desenvolvida de corpo como palco biográfico do ser, o próximo item do estudo vai analisar os discursos que permearam o corpo feminino ao longo da história.

\section{QUEM E O QUE CONSTRUIU (VISIBILIZOU) OS CORPOS FEMININOS AO LONGO DA HISTÓRIA?}

Para além de uma construção histórica, o corpo feminino tornou-se objeto de estudo da filosofia, da medicina, da pedagogia, da psicologia e também do direito (COLLING, 2014). Com isso, estabeleceu-se uma normatização relativa ao corpo feminino que envolve todas suas entrelinhas, não deixando qualquer margem de interpretação e de vivência para o próprio sujeito cuja biografia é escrita em carne feminina. É possível afirmar que isso fez com que na antropologia e na teoria feminista de modo geral, a principal referência tenha sido sempre o corpo interno (o corpo biográfico), relegando-se ao corpo biológico, à carne, à carcaça, um lugar secundário em termos de relevância. Ocorre que, a história das mulheres e da sua luta não se aparta da história de seus corpos.

0 modelo de sociedade reconhecido e aceito até antes dos séculos XVII e XVIII era denominado de organicista ou holista, no qual o Estado era superior e anterior aos indivíduos. A nova referência que surge a partir do século XVIII começa a desenhar uma noção de indivíduo como centro e, portanto, anterior e superior à estrutura do Estado do todo. Em linhas gerais, isso acarreta uma maior tutela do indivíduo singularmente considerado em sua dimensão humana, ou seja, pelo simples fato de ser humano (BEDIN, 1997). Essa onda racionalista trouxe com Descartes uma outra forma de pensar que estabelecia que o acesso ao mundo se dava por meio da racionalidade. Sendo assim, a forma correta, verdadeira e 
legítima para compreender o mundo, acessá-lo, construí-lo e transformá-lo era por meio da razão. Não é preciso dizer que essas circunstâncias fizeram com que o corpo orgânico fosse relegado a um segundo plano. Nesse sentido, para Aníbal Quijano (2005, p. 129):

Com Descartes o que sucede é a mutação da antiga abordagem dualista sobre o "corpo" e o "não-corpo". 0 que era uma co-presença permanente de ambos os elementos em cada etapa do ser humano, em Descartes se converte numa radical separação entre "razão/sujeito" e "corpo". A razão não é somente uma secularização da idéia de "alma" no sentido teológico, mas uma mutação numa nova id-entidade, a "razão/sujeito", a única entidade capaz de conhecimento "racional", em relação à qual o "corpo" é e não pode ser outra coisa além de "objeto" de conhecimento. Desse ponto de vista o ser humano é, por excelência, um ser dotado de "razão", e esse dom se concebe como localizado exclusivamente na alma. Assim o "corpo", por definição incapaz de raciocinar, não tem nada a ver com a razão/sujeito.

O primeiro discurso histórico responsável por determinar os papéis sociais reside em Platão (427-437 AC). O filósofo aproxima parto e pensamento sob o argumento de que pensar é dar à luz. Contudo, quando compara os ofícios do filósofo e da parteira, adverte que o delas é inferior ao seu. De modo geral, assinala que as mulheres são fracas e os homens fortes, quando questiona Glauco da seguinte forma:

Tens conhecimento de alguma atividade humana em que os homens não sobrepujem as mulheres? Estenderemos o nosso discurso mencionando a tecelagem, a confeitaria e a cozinha, trabalhos que parecem apropriados às mulheres e em que a inferioridade dos homens é altamente ridícula? (PLATÃO, 1997, p. 154).

Do mesmo modo, o filósofo grego Aristóteles (384-322 AC) enalteceu a racionalidade masculina em detrimento da feminina. Para ele, "entre os animais, é o ser humano que possui o cérebro mais desenvolvido, em proporção com o seu tamanho; como também o cérebro é maior nos homens do que nas mulheres" (ARISTÓTELES, 2010, p. 79).

Hipócrates (460-377 AC), Pai da Medicina, incorporou Platão e Aristóteles em seu discurso ao afirmar que o útero circulava no interior do corpo da mulher. Acreditava que mulheres que se relacionavam com 
homens tinham melhor saúde. Biologicamente, portanto, corroborava a fragilidade feminina ao mencionar que o corpo da mulher é mais úmido, na medida em que se assemelha a um tecido de lã, ao passo em que o corpo do homem, por ter uma trama menor, mais apertada e densa, retém menos líquido (HIPÓCRATES, 2007).

Outro argumento nesse sentido, de incompletude feminina em termos médicos, era protagonizado por Galeno (130 DC), médico grego, que afirmava que a falta de calor fez com que os órgãos genitais das mulheres não descessem, ficando ocultos. A anatomia masculina, portanto, era vista como exterior e perfeita (BOZON, 2004). De acordo com Foucault (2014, p. 135), Galeno “[...] supõe a emissão de esperma da mulher como no homem, a diferença consistindo em que a elaboração desse humor é menos perfeita e menos completa na mulher: o que explica seu papel menor na formação do embrião".

Em $O$ cuidado de si, Foucault (2014) também analisa $A$ chave dos sonhos, de Artemidoro, para quem a penetração é o qualificador do ato sexual, de modo que sonhos lésbicos significam coisas negativas, até mesmo nos negócios e nas finanças. Isso explica o motivo pelo qual os sonhos, em Artemidoro, são fortemente marcados pela personagem masculina e pela importância atribuída à virilidade. Nesse sentido, o ato sexual é um jogo de poder, entre superior e inferior, em que a penetração é dominação para quem o faz e submissão para quem a ela se sujeita.

Não podemos deixar de referenciar Jean-Jacques Rousseau (17121778), que apesar das inúmeras contribuições teóricas no campo da política e da filosofia, legou incontáveis escritos que, nas palavras de Mary Wollstonecraft (2015), tornaram as mulheres objetos de piedade e desprezo. É particularmente interessante a passagem em Emílio, na qual o genebrino afirma expressamente que a suavidade da mulher sempre pode trazer o marido de volta, apesar de que o marido meigo, por não preservar seu temperamento e suas maneiras particulares de se portar, pode tornar a esposa muito impertinente (ROUSSEAU, 1992).

[...] a primeira e mais importante qualidade de uma mulher é a doçura; feita para obedecer a um ser tão imperfeito quanto o homem, amiúde cheio de vícios e de defeitos, ela deve aprender desde cedo a sofrer até injustiças e a suportar os erros do marido sem se queixar [...]. 0 azedume e a obstina- 
ção não fazem senão aumentar seus males e os maus procedimentos dos maridos (ROUSSEAU, 1992, p. 440)

Cronologicamente, outro argumento médico que pode ser lembrado, ainda que mais atual do que o de Galeno, é o do criminologista Cesare Lombroso (1835-1909), para quem as mulheres eram menos criminosas do que o sexo perfeito - o do macho. Ressalvava, contudo, que a mulher criminosa tinha uma sexualidade exacerbada e embriagada de perversão, fazendo referência à masturbação e ao lesbianismo (LOMBROSO; FERRERO, 2004).

Sigmund Freud (1856-1939), Pai da Psicanálise, também não logrou maiores esforços no sentido de atribuir à mulher um papel social menos opressivo do que o que vinha sendo construído (e ainda hoje o é). Se por um lado o maior expoente do discurso psicanalítico revolucionou ao ouvir os desejos ocultos, inclusive das mulheres, por outro, como todo bom filho de seu tempo, manteve-se conservador quando da construção do sujeito feminino. Para ele, a mulher - ou "continente obscuro", como ele a designava - é um ser incompleto que tem inveja do falo, o que justifica, em algumas situações, a histeria feminina. "O desejo com que a menina se volta para o pai é provavelmente, na origem, o desejo pelo pênis que a mãe não lhe deu e que ela espera receber do pai" (FREUD, 2010, p. 284). Por isso, ele preceitua que o momento mais sublime da vida de uma mulher é quando ela dá à luz a um filho homem.

Por fim, além das narrativas acima, não podemos deixar de mencionar o discurso religioso desde Adão e Eva até a atualidade, o qual reforça a designação do papel do macho e da fêmea, endossando a mulher e notadamente o corpo feminino como um objeto desautorizado de desejo e de gozo, mas também de medo, pecado, intriga e desvio. Nesse sentido, é bastante representativa a passagem na qual Deus dirige-se à Eva e diz: "multiplicarei grandemente a tua dor, e a tua conceição; com dor darás à luz filhos; e o teu desejo será para o teu marido, e ele te dominará" (BÍBLIA, Gênesis, 3-16), ou em Eclesiásticos 25-26, segundo a qual “toda malícia é leve, comparada com a malícia de uma mulher; que a sorte dos pecadores caia sobre ela" (BÍBLIA, Eclesiásticos, 25-26). É sabido que a Igreja Católica Apostólica Romana orientou as leis do direito romano nas legislações ocidentais, daí porque reproduziu-se nelas a inferioridade 
da mulher pregada pela religião, situação a respeito da qual serão feitas maiores considerações no último ponto em estudo.

É evidente que muitos progressos verificam-se dia após dia no que diz respeito ao corpo feminino. Contudo, a contemporaneidade, especialmente no Brasil, apresenta um sadismo muito particular travestido de um certo charme e do qual não podemos nos esquecer. Uma espécie de discurso incrustrado no habitus ${ }^{1}$ a que se refere Pierre Bourdieu (2002). Millôr Fernandes (1923-2012) fez da causa feminista o estopim de um riso fácil em suas colunas da revista Veja ao afirmar, por exemplo, que "o melhor movimento feminino ainda é o dos quadris” (FERNANDES, 2002). Nessa mesma perspectiva, é amplamente conhecia a escancarada obscenidade de Nelson Rodrigues (1912-1980), para quem, em verdadeiro tom de ironia, nem toda mulher gosta de apanhar, somente as normais.

Eis a atmosfera sobre a qual foi enquadrado o corpo feminino. É fácil perceber que todas estas manifestações/apropriações do corpo feminino são protagonizadas por homens e levam em conta um sistema binário, de opostos, em que um dos pares é sempre hierarquizado como superior e o outro inferior. "Há um lado misterioso, irracional e perigoso na feminilidade. Algo de verdadeiro e falso, luz e sombra, escuridão e rutilância. A mulher é um meio dizer que o homem elabora na especificidade do seu desejo [...]" (VALDIVIA, 1997, p. 27).

Diante dessas considerações, não poderia ser outra a conclusão da médica e antropóloga Mari Luz Esteban (2004, p.115-116), no sentido de que "los cuerpos femeninos están hablando, actuando, comunicando, expresando y materializando diferentes visiones del mundo, que no siempre coinciden con lo que se dise sobre ellas". De fato, as mulheres foram inseridas em um discurso de cuja construção não participaram e agora, pouco a pouco, aliando teorizações a movimentos sociais, estão tentando galgar progressos em termos de conquista de direitos e de reconhecimento social.

\section{MOI-PEAU: DECIFRANDO O CORPO (E O MUNDO) FEMININO}

A expressão francesa moi-peau é um conceito da psicologia e da psicanálise desenvolvido por Didier Anzieu (1989), que considera a pele o mais vital dos órgãos, na medida em que é possível viver cego, surdo, 
mudo, sem paladar, sem olfato, mas sem a integridade da maior parte da pele não há como sobreviver. A ideia, nesse ponto do estudo, é demonstrar que o corpo psíquico, biográfico e o corpo somático, biológico, não se separam. E com isso não se está querendo enquadrar e limitar o ser a sua materialidade carnal, muito antes pelo contrário, até mesmo porque sabe-se que, sexualmente falando, não raras vezes o eu não se identifica com o seu gênero de nascimento, como é o caso do transgênero ou transexual, em oposição ao cisgênero.

É no corpo que a vida inscreve os eventos, traços, vivências, experiências e expectativas de cada indivíduo considerado em sua singularidade, o que abarca as situações mais elementares e cotidianas da vida, a exemplo das vacinas tomadas, do braço quebrado por causa da brincadeira de infância, dos procedimentos cirúrgicos, da postura inadequada sustentada durante anos a fio e da exposição excessiva ao sol.

De fato, a partir do século XX, o corpo assume uma função extremamente relevante enquanto mediador cultural, porque ele agora se individualiza e diferencia em relação aos demais, recebendo cada vez mais visibilidade e importância, inclusive em termos econômicos. Passa-se do "penso, logo existo" para uma espécie de "sou carne, logo existo", pois somente o corpo permite ao sujeito agarrar-se a sua própria existência. É nele que o indivíduo escreve sua história, formula suas narrativas e projeta suas expectativas de vida. Nessa perspectiva, não há como negar que muitas das nossas identidades se fazem visíveis aos outros por meio das indústrias de consumo, beleza e publicidade. Para Corbin, Courtine e Vigarello (2011, p. 13):

A história do corpo feminino é também a história de uma dominação na qual os simples critérios de estética já são reveladores: a exigência tradicional por uma beleza sempre 'pudica', virginal e vigiada, impôs-se por muito tempo, antes que se afirmassem libertações decisivas repercutidas nas formas e nos perfis, movimentos mais aceitos, sorrisos mais expansivos, corpos mais desnudos. A história do corpo, em outras palavras, não poderia escapar à história dos modelos de gênero e das identidades.

Essa colocação vai ao encontro das ideias da historiadora social Carol Dyhouse (2011), para quem o glamour, em muitos contextos, engendrou 
um verdadeiro repúdio às normas de classe e gênero ou às expectativas de feminilidade convencionais. Para ela, portanto, o glamour e todos elementos que orbitam em torno dele representaram mais rebelião, ousadia e subversão do que submissão feminina. Nesse mesmo sentido, para Gilberto Freyre (1987, p. 33):

Pode-se dizer da mulher que tende a ser, quanto a modas para seus vestidos, seus sapatos, seus penteados, um tanto maria-vai-com-as-outras. Portanto, a corresponder ao que a moda tem de uniformizante. Mas é da argúcia feminina a iniciativa de reagir contra essa uniformização absoluta, de acordo com características pessoais que não se ajustem a imposições de uma moda disto ou daquilo. Neste particular, é preciso reconhecer-se, na brasileira morena, o direito de repudiar modas norte-européias destinadas a mulheres louras e alvas.

Do mesmo modo, Lipovetsky (1999, p. 117-118), ao fazer suas considerações sobre o que ele chama de o belo sexo, assegura que embora o corpo feminino tenha sido estudado, investigado, decomposto e recomposto, tudo para possibilitar a fama de quem o interpreta - o pintor, o poeta -, não há como assimilar estritamente os hinos ao belo sexo como uma forma de relegação do feminino.

[...] no quepa asimilar pura y simplemente, los himnos al bello sexo a un instrumento de alienación de la mujer; al concretar un reconocimiento y un valoración inéditos de las prerrogativas femeninas, permitieron al mismo tiempo impulsar una promoción social y simbólica de las mujeres. [...] De ahí que la irrupción histórica del bello sexo deba interpretarse menos como una nueva figura de la relegación de lo femenino que como uno de los primeros jalones de la dinámica moderna que engendró el reconocimiento de la dignidad humana y social de la mujer.

0 problema reside no fato de que boa parte das teorizações feministas e da militância consideram a aparência feminina de modo restrito, como se a mulher fosse um ser absolutamente passivo e submetido às leis do mercado e da indústria da beleza, da moda e da estética. Esteban (2004) entende que esse caminho não favorece o empoderamento feminino, pois é preciso fazer da mulher não uma vítima, mas agente de sua própria história. Assim interpretado, o corpo feminino é novamente 
fragmentado, fazendo-se dele um objeto de prazer dentro de um jogo sofisticado e elegante de culto à beleza, à fragilidade e à vulnerabilidade femininas (LIPOVETSKY, 1999). Fazer essa afirmação não significa dizer que as normatizações de gênero não têm consequências maléficas para as mulheres. Pelo contrário, implica em observar a experiência concreta de cada uma delas, sem homogeneizá-las ou convertê-las em seres absolutamente inertes, circunstância que anda passo a passo com a vitimização. É fundamental, portanto, reconhecer que as mulheres têm capacidade para gerar propostas alternativas para, ao menos, compensar a situação de desvantagem à qual estão submetidas.

É evidente que o fato de que rostos envelhecidos não aparecem com frequência na mídia, por exemplo, comunica uma mensagem que, embora sutil, implica na consciência corporal de mulheres e meninas. Ocorre que, é preciso trabalhar com a ideia de que homens e especialmente mulheres negociam seu lugar na sociedade a partir da administração da materialidade corporal, da imagem e da estética.

Os discursos feministas, por conseguinte, têm tido de lidar com a necessidade patente de se adaptar às novas modificações e regulações dos corpos das mulheres, as quais implicam em novas definições de feminino, de mulher e de feminilidade. 0 feminismo do final do século XX levantava a bandeira da tutela de direitos de reprodução (ou de não reprodução), o que implicava em um olhar sexual e erotizado sobre o corpo. $\mathrm{O}$ século XXI, por outro lado, fez do corpo um objeto econômico, de consumo, de exibição e de visibilização. Por isso, pode-se afirmar que o corpo feminino da contemporaneidade é, em boa medida, o corpo da estética, da imagem, do visível, do visto.

No que diz respeito especificamente à questão de gênero, concorda-se com o posicionamento de Esteban (2004) de que parcela considerável do problema da desigualdade entre homens e mulheres reside na definição absolutamente sectária de feminino e de masculino que atribui a cada corpo biológico características estéticas e até mesmo trejeitos que devem ser performados pelo macho ou pela fêmea. 0 masculino é associado à força, à virilidade, ao trabalho, ao passo em que o feminino adorna a beleza, a maternidade, a reprodução e a sensualidade - o sex appeal. 
Nessa perspectiva, é bastante ilustrativo que a morena e especialmente a negra tenham sido marcadas por um caráter erótico em nossa cultura. Em terras portuguesas, por exemplo, havia uma atração especial pelos cabelos louros. Todavia, a morena e a negra eram preferidas para o amor erótico, físico, carnal. A própria literatura dos séculos XVIII e XIX delineia claramente esse apreço masculino relativamente à morena e à pele escura, aos cabelos negros em grande quantidade e aos olhos de jabuticaba. A loira, por sua vez, estava relacionada às classes altas (PRIORE, 2000). É curioso pensar que, ainda hoje, a grande maioria das mulheres vítimas de violência sexual seja formada por mulheres negras e pardas (NOVAES, 2016), como se o corpo delas estivesse à disposição e fosse essa sua destinação natural. É claro que essa exclusão remonta ao período escravocrata. Mas o que é a cor da pele, se não a cor do corpo, a cor do ser? Esse exemplo demonstra de forma muito emblemática o motivo pelo qual o empoderamento feminino deve ocorrer por meio da (e na) materialidade carnal.

Boa parte das diferenças e particularidades que foram desenhadas para cada gênero se reflete nas formas de vestir. E aqui cabe lembrar Lipovetsky (2004), para quem a moda não é somente um produto da sociedade de consumo, mas uma instituição social. Nesse sentido, cabe trazer para o debate matéria de maio de 2016 veiculada na revista Estilo, cuja temática gira em torno da neutralidade de gênero que aparece agora nas formas de vestir e de consumir. A tendência andrógina é, de fato, contemporânea, mas começou a se delinear na Primeira Guerra Mundial (1914-1918), tendo em vista que as mulheres precisaram assumir o trabalho que os homens não mais podiam fazer em razão de que estavam nos campos de batalha.

Em 1966, Yves Saint Laurent cria o unissex Le Smoking. Jean Paul Gaultier, em Paris, Alexandre Herchcovitch, em São Paulo e a espanhola Zara apostam cada vez mais em coleções underground cujas peças podem ser utilizadas simplesmente por pessoas, independentemente do sexo. Esses "exemplos recentes mostram que o não-gênero pode ter potencial para transformar a forma como consumimos” (GARCIA, 2016, p. 36).

Ainda nessa perspectiva do mundo da moda, é sintomático também que a americana Pantone Inc., mundialmente conhecida por ter desen- 
volvido o primeiro sistema de cores em 1963, tenha selecionado como a cor do ano de 2016, pela primeira vez na história, uma mistura de duas tonalidades: Rose Quartz, um rosa acolhedor como um abraço, e Serenity, tom azulado mais frio e tranquilo, de acordo com as descrições da própria empresa. A escolha foi feita em clara alusão aos movimentos de igualdade de gênero e fluidez em termos de moda.

A historiadora Mary Del Priore (2000) é relativamente cética no que diz respeito aos padrões de beleza e de estética. Ela afirma que as mulheres do século XXI trocaram a submissão aos pais, companheiros, patrões e ao patriarcado de um modo geral, pela dominação da mídia e da publicidade e das suas imposições. Não que isso não ocorresse em outros tempos, mas é preciso concordar que em tempos de globalização (econômica, cultural, política, social, tecnológica e estética, inclusive) a figura do corpo ideal resta estandardizada. De fato, "não há prisão mais violenta do que aquela que não nos permite mudar" (PRIORE, 2000, p. 99).

Nesse sentido, o corpo feminino e suas facetas podem colaborar para o empoderamento de mulheres e para a conquista de direitos e reconhecimento. 0 corpo deve ser compreendido não como a prisão do ser, mas como sua libertação, não como castração, mas como possibilidades dentro (e fora) das liberdades que a vida oferece. Nesse sentido, a hipervisibilização do corpo não é interpretada negativamente, mas enquanto catalisador do empoderamento feminino.

Na realidade, o problema não está na visibilização do corpo feminino - até mesmo porque ele tem sido visibilizado astronomicamente, dia após dia, na publicidade, na indústria pornográfica, na $\operatorname{arte}^{2}$ - mas na forma como ela se dá. É preciso agora, ver o não visto. Em resumo, não se pode reduzir o ser ao corpo, à carcaça, mas também não se pode reduzir o corpo ao ser, à mente. É preciso analisar ambas as dimensões de forma conjunta, fazendo do corpo sujeito e agente de transformação social, porque estamos condenados a viver em nosso invólucro. A psicanálise endossa esse argumento ao afirmar que é através do outro que a unidade corpórea é prefigurada e antecipada. Por isso, o psiquiatra e psicoterapeuta brasileiro Joel Birman (1999, p. 35) afirma que a cons- 
trução do eu e do corpo unificado "são as duas faces da mesma realidade, pois para o sujeito a experiência de ter e ser eu implica para ele habitar um corpo unificado. A condição de unificado remete à noção de ser um, uno, eu, matéria, corpo que se inscreva no espaço e no mundo".

Nesse mesmo sentido, para Foucault (2006, p. 233):

My body, in fact, is always elsewhere. It is tied to all the elsewhere of the world. And to tell the truth, it is elsewhere than in the world, because it is around it that things are arranged. It is in relation to it - and in relation to it as if in relation to a sovereign - that there is a below, an above, a right, a left, a forward and a backward, a near and a far. The body is the zero point of the world.

Na linha da argumentação defendida por Esteban (2004), acredita-se que o empoderamento feminino e, portanto, a emancipação das mulheres, ocorrerá por meio do corpo delas, ou não ocorrerá. Isto porque é o próprio corpo orgânico, de carne, sangue e humores, o local simbólico sobre o qual foram construídas aproximações, definições e padronizações que relegam à mulher uma posição secundária na sociedade, de modo que "el estudio del género no puede escapar al cuerpo, a su materialidad, a la interacción social y corporal” (ESTEBAN, 2004, p. 243).

Dito de outro modo, o corpo não se limita a um espaço da sociedade e da cultura no qual se inscrevem biografias. Ele é objeto, mas, acima de tudo, o próprio ser e, portanto, sujeito. “[...] Talvez já se possa afirmar não que o sujeito tem um corpo, mas que o sujeito é um corpo, pois se está falando de algo que é uno na subjetividade e na corporeidade, uma articulação singular" (LAZZARINI; VIANA, 2006, p. 243).

Por fim, é de se afirmar que empoderar não é sinônimo de embelezar, glamourizar, performar, estereotipar, mas de possibilitar que mulheres aceitem seus corpos e reconheçam a pluralidade de formas e curvas que desenham a(s) silhueta(s) feminina(s) e as suas vivências, porque essas duas dimensões - corpo e mente - não se separam, porque em última instância, todas as contradições e disputas sociais (classe social e idade, por exemplo) implicam na materialidade do corpo.

Por isso, Esteban (2014) conclui que nós, mulheres, estamos condenadas a potencializar nossa consciência corporal - ou nosso 
"cuidado de si", para evocar uma expressão foucaultiana (2014). A mulher é convocada a ser, mais do que nunca, extremamente narcisista (em termos de autoconhecimento) em relação ao seu corpo. Isso implica em visibilizar experiências corporais positivas, na medida em que elas podem engendrar uma influência muito direta e benéfica no tocante à subjetividade da mulher. Em linhas gerais, Esteban propõe que seja possível transformar o itinerário corporal do sujeito, resistindo e contestando as estruturas sociais. Todavia, para que isso ocorra, "tanto el feminismo como la antropología deberían abandonar definitivamente la descorporeización que vienen padeciendo y tomar en cuenta de una vez por todas la carnalidad de la experiencia humana" (ESTEBAN, 2004, p. 245).

No que diz respeito às experiências corporais positivas, é importante o apontamento feito por Mariella Pandolfi a partir do estudo de relatos femininos sobre sintomas e enfermidades, no sentido de que "cette manière et plus complexe de reconter em se racontant montre que dans la vie sociale, les femmes ont tendance à se construire une identité partielle à partir des défaites, des evénements négatifs [...]"(PANDOLFI, 1993, p. 66). Michele Perrot (2003, p. 26) advoga a "necessidade de as mulheres se apropriarem delas, de lutarem pelo conhecimento e pela autonomia de seu corpo, grande bandeira do feminismo contemporâneo". Enfim, acredita-se que somente o empoderamento e a emancipação relacionados à imagem corporal possibilitarão, pouco a pouco, o reconhecimento e progresso em termos de igualdade de gênero.

Para finalizar esse ponto do trabalho, é possível citar a obra Le Viol, do surrealista belga René Magritte. A pintura é verdadeiramente perturbadora e coloca o observador a perguntar-se sobre o que efetivamente se vê: seria um corpo em uma cabeça ou uma cabeça em um corpo? Magritte visibiliza um corpo que, em tese, estaria fora do campo de visão da moldura. Com isso, pretende-se reiterar, de outra forma, o que já foi dito até aqui, no sentido de que se há um ser, há também a materialidade carnal. Ambas as dimensões se misturam, dando forma e substância a cada indivíduo particular. 


\section{"YOUR BODY IS A BATTLEGROUND": O DIREITO SE APROPRIA DO CORPO FEMININO}

A sentença que dá nome ao último ponto desse texto também denomina a serigrafia fotográfica em vinil da artista gráfica feminista Barbara Kruger. A obra foi produzida em apoio à liberdade reprodutiva e, portanto, em clara alusão ao fato de que o corpo feminino é um campo de batalha simbólico no qual são travadas as lutas que inscrevem no sujeito cujo corpo biológico é feminino uma narrativa pré-determinada. É arte, mas também é protesto. Em termos teóricos, para Carolina González Laurino (2008, p. 18-19):

El cuerpo aparece como la expresión material que traduze un conjunto de ideas y símbolos y muestra, en el plano estético, el diseño de un sujeto socialmente modelado. La trayectoria vital aparece, pues, corporeizada en una forma que comunica socialmente a pesar del sujeto.

É fato que o corpo vem sendo palco de lutas públicas das mulheres de uma forma nunca antes vista ou talvez imaginada. Por isso, Lipovetsky (1999) vai afirmar que a mulher contemporânea ou a "terceira mulher" é uma verdadeira incógnita. A primeira mulher era diabolizada e depreciada. A segunda foi colocada em um pedestal. Apesar das diferenças de tratamento, em todos os casos a mulher vinha sendo pensada, elaborada e construída em relação ao - e pelo - homem. Sua forma de ser e estar no mundo se ordenava a partir de situações pré-estabelecidas: casar, ter filhos, administrar as tarefas domésticas e cuidar do marido. Para elas, o privado. Para eles, o que quisessem.

Agora, pela primeira vez na história, o destino feminino entra em uma era de total imprevisibilidade que, em boa medida, deriva da gama enorme de opções que hoje são disponibilizadas às mulheres, ainda que em menor quantidade do que ocorre com relação aos homens. "Todo, en la existencia femenina, es ahora objeto de elección, de interrogación y de arbitraje" (LIPOVETSKY, 1999, p. 219). Quando essa possibilidade de autodeterminação desagua no corpo da mulher, nas suas curvas, na sua mobilidade e nas suas inconstâncias, o direito é convocado a manifestar- 
-se sob a lógica do lícito-ilícito, regulando e, por consequência, podando as liberdades e possibilidades da carne. Com efeito, quando as mulheres deixam de ser cúmplices do papel do falo, os elementos traumáticos do machismo ficam ainda mais evidentes (GIDDENS, 1993).

Neste ínterim, a aplicação uniforme de normas jurídicas está relacionada ao respeito à igualdade formal típica da Modernidade, mas também à exigência de segurança jurídica do modelo liberal. Ocorre que, na contemporaneidade, não há como desconsiderar as novas demandas sociais, encabeçadas pela diferença, pelo pluralismo e pela diversidade, em nome da ordem, da certeza e da igualdade formal.

A globalização tornou evidente (ou ao menos possibilitou) o surgimento da imensa diversidade que até então vinha sendo acobertada pelo manto fictício da igualdade. Nesse sentido, Warat (2000) vai afirmar que a igualdade é castração, ou seja, poda, verdadeira aniquilação dos desejos que pulsam em cada ser humano relativamente a sua diversidade e a sua vontade de, talvez, ser diversas coisas. Por isso, é possível concluir que a igualdade surge como um instituto que narra o mundo com a ocultação de toda beleza e intensidade do caos, da desordem, da incerteza, da diversidade e do pluralismo. Nessa tendência de desconfiança diante das grandes narrativas, a questão do corpo aparece de forma muito emblemática.

Portanto, não é por obra do acaso que as sociedades ocidentais da Modernidade tenham conformado uma experiência a partir da qual os sujeitos se significam em termos de sexualidade dentro de um sistema de controle heteronormativo, cuja lógica é binária e claramente hierárquica (SANTOS; LUCAS, 2015). Por isso Foucault (1979, p. 262) afirma que "com seu sexo, você não vai simplesmente fabricar prazer, você vai fabricar verdade", porque assim como a palavra do louco denuncia a loucura dele, o meu sexo vai falar sobre meu corpo, sobre minha essência, sobre minha verdade, enfim, sobre meu eu.

Então, quando os corpos (e, não é preciso dizer, o ser) se significam, se vestem, performam, amam, desejam, em síntese, existem de formas diferentes daquelas pré-estabelecidas relativamente à experiência da materialidade corporal, a cultura contemporânea cria os dispositivos necessários para correção e transformação desse corpo anormal, normalizando, regulando, castrando. Outrossim, ainda que o sistema jurídico 
tente incluir ele o faz excluindo. Ou seja, reconhecer uma conduta do corpo implica em excluir as demais, as quais vão postular equivalente reconhecimento, e essa parece ser a lógica esquizofrênica de uma sociedade que se fragmentou e se capilarizou tanto a ponto de postular uma espécie de certificação em absolutamente todas suas facetas.

Ocorre que, a experiência corporal se tornou tão diversificada e sortida que o direito e seus institutos não dão mais conta (se é que algum dia deram) da tarefa de disciplinar todas as condutas relativas aos corpos. Nesse sentido, Richard Miskolci (2006) pondera que a sociedade contemporânea vem propondo, incessantemente, meios técnicos para solucionar questões que somente seriam efetivamente resolvidas por modificações sociais profundas. De fato, corporificar as identidades por meio do direito, acarreta, ainda que não propositalmente, uma redução de toda complexidade humana às formas físicas e visíveis.

De fato, o tratamento que o direito dispensa ao corpo é arbitrário porque geralmente vai implicar em uma separação abismal entre homens e mulheres. Embora ocorra uma certa resistência dos corpos aos disciplinamentos, não se pode negar que é sempre uma limitação. 0 que se pretende demonstrar é que o direito não deveria ser um instituto utilizado para regular absolutamente todas as experiências e representações corporais. É evidente que existem disposições legais a respeito da materialidade carnal que são de fundamental importância, - como o corpo inacessível da criança, por exemplo - mas levar essa prerrogativa ao extremo significa interferir na vida privada dos indivíduos de forma totalmente arbitrária.

Quando o art. 13 do Código Civil dispõe que "salvo por exigência médica, é defeso o ato de disposição do próprio corpo, quando importar diminuição permanente da integridade física, ou contrariar os bons costumes", o que ele nos diz? O que seriam os bons costumes? Nessa perspectiva, o corpo como libertação e potência do ser é negado.

No que toca especificamente o corpo feminino, verifica-se que o direito se apropria dele de forma bem específica, regulando condutas relativas à reprodução, contracepção, aborto, prostituição ${ }^{3}$ e esterilização (sobretudo em mulheres jovens), ou seja, à sexualidade de um modo geral. Isto deriva do fato de que o corpo feminino sempre foi ou 
demonizado ou colocado em um pedestal, de modo que ou a mulher era associada ao matrimônio e à maternidade e, portanto, pura, ou ao satã e, por conseguinte, impura.

Em que pese tenhamos presenciado avanços muito significativos em termos de conquista de direitos das mulheres, retrocessos são denunciados o tempo todo. Portanto, não causa estranheza - embora devesse causar - que o Senado Federal, por meio de sua página na rede social facebook, tenha indagado se "as brasileiras devem perder o direito legal de interromper a gravidez resultante de estupro". Situações como essa somente corroboram o fato de que os direitos humanos são institutos verdadeiramente frágeis e permeados por relações de poder, motivo pelo qual a luta em seu favor deve ser um exercício constante, notadamente dos grupos vulneráveis, a exemplo das mulheres.

Foucault (1997) tinha razão quando afirmava que aprender a comportar-se, movimentar-se, ser preciso e ritmado, são gestos e sentimentos fabricados, produzidos. Este adestramento todo é resultado da aplicação de técnicas positivas - e não apenas de repressão - pois agem no desejo e no saber, de modo que o corpo torna-se útil e eficiente, mas ao mesmo tempo dócil e submisso. Tomemos como exemplo a Lei no 9.263 de 1996, que dispõe sobre planejamento familiar. Ela estabelece os casos restritos nos quais é permitida a esterilização voluntária, sendo que o homem ou a mulher devem ter mais de 25 anos de idade, capacidade civil plena ou no mínimo dois filhos vivos. Na parte final do inciso I, consta expressamente que é possível submeter a pessoa interessada a um aconselhamento multidisciplinar, "visando desencorajar a esterilização precoce". Quer dizer, se o Estado adotasse uma política em sentido contrário, quer dizer, de redução de natalidade, é evidente que uma lei nesses termos sequer existiria em nosso ordenamento. De fato, o sistema de controle dos corpos é perverso e ao mesmo tempo genial, porque simplesmente não nos damos conta do poder que é exercido sobre nós.

0 direito diz muito quando positiva uma situação no ordenamento, mas diz ainda mais quando não diz nada. Quer dizer, quando se omite as consequências são tão severas quanto aquelas oriundas do reconhecimento expresso e taxativo de uma determinada circunstância. Nesse 
aspecto, é emblemático que o bissexual não encontre respaldo legal para abordar sua sexualidade, porque do ponto de vista do sistema jurídico ele simplesmente não existe. Por isso, Judith Butler (2015) vai afirmar que é preciso visibilizar os corpos, na medida em que aqueles que se materializam obtêm legitimidade social. Por outro lado, o corpo desprezado pela norma é relegado à invisibilidade, à indiferença.

Esses são apenas alguns exemplos, mas que já permitem concluir que a experiência corporal se tornou tão diversificada e sortida que o direito, enquanto norma jurídica, simplesmente não dá conta da tarefa de regular todas as condutas a ela relativas, porque acima de tudo o corpo não é algo que se tem, mas algo que se é. 0 grande contrassenso talvez esteja relacionado ao fato de que quanto mais o direito busca proteger a integridade corporal do ser humano por meio da norma, mais o indivíduo recebe autonomia da vontade para dela dispor. Em última instância, esses caminhos não se cruzam, ou seja, são inconciliáveis, e é nesse horizonte que os corpos se fazem, se desenvolvem e existem, alheios à disciplinarização, cada vez mais opressora, mas também menos eficaz.

\section{CONSIDERAÇÕES FINAIS}

O presente estudo objetivou demonstrar, num primeiro momento, que o corpo feminino sempre foi narrado por homens a partir de um sistema binário que hierarquizava o homem como superior e a mulher como inferior. Platão, Aristóteles, Hipócrates, Galeno, Freud, Rousseau. Todos utilizaram, cada qual a sua maneira, o discurso de que a inferioridade da mulher é natural, dando suporte a práticas jurídicas e constitucionais de regulamentação entre os sexos, justificando-se a inferioridade e a submissão feminina.

Não se pode negar que salvo raras comunidades matriarcais existentes no mundo hoje, a maioria dos povos - inclusive o ocidental - organizou-se e ainda hoje desenvolve-se de modo que as mulheres e meninas estão, em maior ou menor escala, constantemente expostas à violência oriunda da desigualdade de gênero. Todavia, a sociedade contemporânea tem vivenciado uma verdadeira subversão do papel que foi atribuído à 
mulher ao longo da história, de modo que atualmente os corpos femininos assumem uma forma de ser e estar no mundo que nem sempre - ou raramente - coincide com o que se disse sobre eles.

Por isso, é imperioso reconhecer que a história das mulheres contada e efetivamente vivida por elas - é, ao contrário do que se pensa, muito recente, e em certa medida ela coincide com a visibilização do corpo feminino. Tanto é assim que os movimentos feministas contemporâneos assumem uma postura de defesa contumaz da ideia de "meu corpo, minhas regras". Apesar de alguns significativos avanços, as sociedades contemporâneas desenvolveram formas tão sofisticadas e sutis para exercer o controle sobre os corpos que sequer percebemos tal circunstância sem um exercício atento e crítico do nosso entorno.

Para além disso, o estudo procurou demonstrar que até mesmo nas sociedades liberais ocidentais, a exemplo da brasileira, os direitos humanos devem ser compreendidos como um processo de luta constante e ininterrupto, pois os setores mais conservadores do Congresso Nacional estimulam e promovem retrocessos que atingem consideravelmente os direitos dos grupos mais vulneráveis, dentre os quais incluem-se as mulheres. Nesse sentido, as entrelinhas da legislação brasileira evidenciam o perverso e refinado aparato de controle dos corpos femininos, especialmente no que diz respeito à sexualidade, porque esse aspecto da vida é, por excelência, um modo de expressão, mas também de significação, e não há maneira mais vil de exercer o poder do que regulando a intimidade do sujeito.

Conclui-se, portanto, que mais do que um espectador passivo, o corpo orgânico pode ser um caminho para a libertação, sendo necessário, para tanto, estimular o autoconhecimento e o amor próprio em relação ao próprio corpo. 0 desafio, agora, é construir uma nova visão de mundo a partir de narrativas que concebem o corpo biológico da mulher não mais como objeto, mas como sujeito, como protagonista e agente da sua própria história. 0 poema de Galeano pressagia o que talvez esteja acontecendo com nossos corpos: estamos subvertendo a ideia de corpo como culpa, máquina e negócio, para vivê-lo como festa. 


\section{NOTAS}

1 É possível afirmar que o habitus de Bourdieu (2002) se refere à forma como a sociedade, de maneira geral, incorpora em seu modo de agir, pensar e sentir determinadas estruturas sociais.

2 Nesse aspecto, é interessante mencionar os rumores envolvendo a revista Playboy, que em novembro de 2015 anunciou o fim da revista, embora tenha voltado a publicar. Em boa medida, sua retirada do mercado justifica-se pelo aumento explosivo da pornografia online, o que causou queda brusca nas vendas.

3 Atualmente, a prostituição é legalizada no Brasil e reconhecida como profissão. Embora esteja em tramitação na Câmara dos Deputados o PL 4211/2012, de autoria do deputado Jean Wyllys (PSOL-RJ), não há regulamentação específica para o exercício da profissão, o que dificulta a obtenção de benefícios oriundos da relação de trabalho.

\section{REFERÊNCIAS}

ANZIEU, Didier. 0 eu-pele. São Paulo: Casa do Psicólogo, 1989.

ARISTÓTELES. Partes dos animais. Tradução de Maria Fátima Souza e Silva. Lisboa: Imprensa Nacional - Casa da Moeda, 2010.

BEDIN, Gilmar Antonio. Os direitos do homem e o neoliberalismo. Ijuí: Ed. Unijuí, 1997.

BÍBLIA. Português. Bíblia Sagrada. Petrópolis: Vozes, 2005.

BIRMAN, Joel. Cartografias do feminino. São Paulo: Editora 34.

BOURDIEU, Pierre. A dominação masculina. Tradução de Maria Helena Kühner. 2. ed. Rio de Janeiro: Bertrand Brasil, 2002.

BOZON, Michel. Sociologia da sexualidade. Tradução de Lourdes Menezes. Rio de Janeiro: Ed. FGV, 2004.

BRASIL. Lei no 10.406, de 10 de janeiro de 2002. Código Civil. Brasília, 2002. Disponível em: http://www.planalto.gov.br/ccivil 03/leis/2002/l10406.htm. Acesso em: 26 jun. 2016.

. Lei no 9.263, de 12 de janeiro de 1996. Regula o § 7ํ do art. 226 da Constituição Federal, que trata do planejamento familiar, estabelece penalidades e dá outras providências. Brasília, 1996. Disponível em: http://www.planalto.gov. br/ccivil 03/leis/L9263.htm. Acesso em 03 jul. 2016. 
BUTLER, Judith. Cuerpos que importan: sobre los límites materiales y discursivos del "sexo". 2. ed. Buenos Aires: Paidós, 2015.

COLLING, Ana Maria. Tempos diferentes, discursos iguais: a construção do corpo feminino na história. Dourados: Ed. UFGD, 2014.

CORBIN, Alain; COURTINE, Jean-Jacques; VIGARELLO, Georges. História do corpo: as mutações do olhar: o século XX. Tradução e revisão de Ephraim Ferreira Alves. 4. ed. Petrópolis: Vozes, 2011.

DYHOUSE, Carol. Glamour: mujeres, historia y feminismo. Traducción de Jeannine Emery. Buenos Aires: Claridad, 2011.

ESTEBAN, Mari Luz. Antropologia del cuerpo: género, itinerários corporales, identidade y cambio. Espanha: Ed. Bellaterra, 2004.

FEATHERSTONE, Mike. Trasformazioni. Corpo, imagine ed affect nella cultura dei consumi. In: Identità incorporate. Segni, immagini, differenze. GUIZZARDI, Gustavo. Bologna: Mulino, 2009.

FERNANDES, Millôr. Millôr Definitivo: a bíblia do caos. Porto Alegre: L\&PM, 2002.

FOUCAULT, Michel. Microfísica do poder. Tradução de Roberto Machado. Rio de Janeiro: Ed. Graal, 1979.

História da sexualidade: o cuidado de si. Tradução de Maria Thereza da Costa Albuquerque. São Paulo: Paz e Terra, 2014.

Utopian body. In: JONES, Caroline A (Org.). Sensorium: embodied experience, technology and contemporary art. Cambridge, M/A London: The MIT Press Copublished with the MIT List Visual Arts Centre, 2006, p. 229-234.

FREUD, Sigmund. 0 mal-estar na civilização, novas conferências introdutórias à psicanálise e outros textos (1930-1936). Tradução de Paulo César de Souza. São Paulo: Companhia das Letras, 2010.

FREYRE, Gilberto. Modos de homem, modas de mulher. Rio de Janeiro: Record, 1987. 
GALIMBERTI, Umberto. Il corpo. 20.ed. Milano: Feltrinelli, 2010.

GARCIA, Claudia. Será o fim do gênero na moda? In Style: Estilo de Vida. São Paulo, no 164, maio 2016, p. 34-37.

GIDDENS, Anthony. A transformação da intimidade: sexualidade, amor e erotismo nas sociedades modernas. Tradução de Magda Lopes. São Paulo: Ed. UNESP, 1993.

HIPÓCRATES. Aforismos. São Paulo: Martin Claret, 2007.

LAURINO, Carolina González. Identidad y percepción social del cuerpo. In: PRZECANSKI, Teresa (Org.). El cuerpo y sus espejos: estudios antropológicoculturales. Montevideo: Planeta, 2008.

LIPOVETSKY, Gilles. La tercera mujer: permanencia y revolución de lo femenino. Traducción de Rosa Alapont. Barcelona: Ed. Anagrama, 1999.

. Os tempos hipermodernos. Tradução de Mário Vilela. São Paulo: Ed. Barcarolla, 2004.

LOMBROSO, Cesare; FERRERO, Guglielmo. Criminal woman and prostitute and the normal woman. Translated by Nicole Hahn Rafter and Mary Gibson. Durham: Duke University, 2004.

MISKOLCI, Richard. Corpos elétricos: do assujeitamento a estética da existência. Estudos Feministas, Florianópolis, v. 14, n.3, p. 272, set/dez. 2006.

NOVAES, Marina. "É preciso discutir por que a mulher negra é a maior vítima de estupro no Brasil". Disponível em: http://brasil.elpais.com/brasil/2016/07/14/politica/1468512046 029192.html, 2016. Acesso em: 28 jul. 2016.

PANDOLFI, Mariella. Le self, le corps, la "crise de la présence". Anthropologie et Sociétés, 1993, vol. 17. no 1-2, pp. 57-77.

PERROT, Michele. Os silêncios do corpo da mulher. In: MATOS, Maria Izilda Santos de; SOIHET, Rachel. 0 corpo feminino em debate. São Paulo: Ed. UNESP, 2003. pp. 13-27. 
PLATÃO. A república. Tradução de Enrico Corvisieri. São Paulo: Ed. Nova Cultural, 1997.

Diálogos. Fédon ou da alma. São Paulo: Ed. Nova Cultural, 1996.

PRIORE, Mary Del. Corpo a corpo com a mulher: pequena história das transformações do corpo feminino no Brasil. São Paulo: Ed. SENAC, 2000.

QUIJANO, Aníbal. Colonialidade do poder, eurocentrismo e América Latina. In: LANDER, Edgardo (org). A colonialidade do saber: eurocentrismo e ciências sociais. Perspectivas latino-americanas. Buenos Aires, Colección Sur Sur, 2005, pp.118-142.

RESTA, Eligio. L'identità nel corpo. In: RODOTÀ, Stefano; ZATTI Paolo. Il governo del corpo. Giufrrè Editore: Milano 2011.

RESTA, Eligio. Le stelle e le masserizie. Paradigmi dell'osservatore. Roma-Bari: Laterza 1997.

ROUSSEAU, Jean-Jacques. Emílio ou da educação. Tradução de Sérgio Milliet. Rio de Janeiro: Bertrand Brasil, 1992.

SANTOS, André Leonardo Copetti; LUCAS, Doglas Cesar. A (in)diferença no direito. Porto Alegre: Livraria do Advogado, 2015.

VALDIVIA, Olivia Bittencourt. Psicanálise e feminilidade: algumas considerações. Psicol. cienc. prof., Brasília, v. 17, n. 3, p. 20-27, 1997. Disponível em: http://www.scielo.br/scielo.php?script=sci arttext\&pid=S141498931997000300004\&lng=en\&nrm=iso. Acesso em: 15 jul. 2016.

WARAT, Luis Alberto. A ciência jurídica e seus dois maridos. 2. ed. Santa Cruz: EDUNISC, 2000.

WOLLSTONECRAFT, Mary. Reivindicação dos direitos das mulheres. Tradução e notas de Andreia Reis do Carmo. São Paulo: EDIPRO, 2015.

Recebido em: 6-9-2016

Aprovado em: 24-2-2017 


\section{Doglas Cesar Lucas}

Pós-Doutor em Direito pela Università Degli Studi di Roma Ter; Doutor em Direito pela UNISINOS (2012); mestre em Direito pela Universidade Federal de Santa Catarina; professor dos Cursos de Graduação e de Mestrado em Direito na Universidade Regional do Noroeste do Estado do Rio Grande do Sul - Unijui e professor tempo parcial no Curso de direito do Instituto Cenecista de Ensino Superior Santo Ângelo; hefe do Departamento de Ciências Jurídicas e Sociais da Unijuí; avaliador do MEC/INEP. E-mail: doglasl@unijui.edu.br

Universidade Regional do Noroeste do Estado do Rio Grande do Sul, Departamento de Estudos Jurídicos. Rua do Comércio, 3000. Universitário. CEP 98700-000 - Ijui, RS - Brasil.

\section{Pâmela Copetti Ghisleni}

Acadêmica e Bolsista CAPES do Curso de Mestrado em Direitos Humanos do PPGD da Universidade Regional do Noroeste do Estado do Rio Grande do Sul - UNIJUÍ. Membro da Comissão de Direitos Humanos da 23a Subseção da OAB de Ijuí/RS. E-mail: pcghisleni@gmail.com

Universidade Regional do Noroeste do Estado do Rio Grande do Sul, Departamento de Estudos Jurídicos. Rua do Comércio, 3000. Universitário. CEP 98700-000 - Ijui, RS - Brasil. 
